\title{
Fecal Glucocorticoid Metabolite Concentration as a Tool for Assessing Impacts of Interventions in Humboldt Penguins (Spheniscus humboldti)
}

\author{
Shangzhe Xie ${ }^{1,2, *(D)}$ and Todd J. McWhorter ${ }^{2}$ (D) \\ 1 Wildlife Reserves Singapore, 80 Mandai Lake Road, Singapore 729826, Singapore \\ 2 School of Veterinary and Animal Sciences, Roseworthy Campus, University of Adelaide, \\ Roseworthy, SA 5371, Australia; todd.mcwhorter@adelaide.edu.au \\ * Correspondence: shangzhe.xie@wrs.com.sg
}

check for updates

Citation: Xie, S.; McWhorter, T.J. Fecal Glucocorticoid Metabolite Concentration as a Tool for Assessing Impacts of Interventions in Humboldt Penguins (Spheniscus humboldti). Birds 2021, 2, 106-113. https://doi.org/ 10.3390/birds2010007

Academic Editor: Jukka Jokimäki

Received: 2 February 2021

Accepted: 24 February 2021

Published: 1 March 2021

Publisher's Note: MDPI stays neutral with regard to jurisdictional claims in published maps and institutional affiliations.

Copyright: (c) 2021 by the authors. Licensee MDPI, Basel, Switzerland. This article is an open access article distributed under the terms and conditions of the Creative Commons Attribution (CC BY) license (https:/ / creativecommons.org/licenses/by/ $4.0 /)$.
Simple Summary: It is difficult to measure stress in penguins without actually causing stress. Measuring the stress hormone corticosterone in the feces of penguins may be the most practical and minimally invasive way of monitoring their stress levels. This study investigated the reliability of immunoreactive fecal glucocorticoid metabolites (FGCMs) for monitoring stress levels in captive Humboldt Penguins at Jurong Bird Park, Singapore. Humboldt Penguin feces were collected from the exhibit for 2 months. The penguins were restrained and transported on three separate occasions during the collection period to simulate stressful events. The FGCM levels in these fecal samples showed that there were significant increases lasting 3 to 7 days in the levels after a stressful event. This method was then used to test whether vests used for monitoring behavior caused stress in penguins, and it was found that they did not. The results indicated that FGCMs can be an accurate indication of capture-, restraint-, and transport-related stress in Humboldt Penguins, and that accelerometer vests do not appear to cause stress.

Abstract: It is currently unknown if current guidelines for collecting and interpreting blood corticosterone in flying birds can be extrapolated to penguins. It is also difficult to collect blood quickly without causing stress to a penguin. Therefore, immunoreactive fecal glucocorticoid metabolites (FGCMs) may be the most practical and minimally invasive way of monitoring the stress levels of penguins. This study investigated the reliability of FGCMs for monitoring stress levels in captive Humboldt Penguins (Spheniscus humboldti) at Jurong Bird Park, Singapore. Humboldt Penguin feces were randomly sampled and pooled from the exhibit for 2 months. The penguins were restrained and transported on three separate occasions to simulate stressful events. The feces were analyzed using an enzyme immunoassay to measure corticosterone levels. There were significant increases lasting 3 to 7 days in the FGCM levels after a stressful event. This method was then used to test whether accelerometer vests used for behavior quantification caused stress responses in these birds. There was no significant difference in FGCMs between time periods with and without the accelerometer vests. The results indicated that FGCMs can be an accurate indication of capture-, restraint-, and transport-related stress in Humboldt Penguins, and that accelerometer vests do not appear to cause stress.

Keywords: accelerometer vest; fecal glucocorticoid metabolites; Humboldt Penguin; non-invasive monitoring; stress

\section{Introduction}

Humboldt Penguins (Spheniscus humboldti) are found in coastal Peru, Chile, Colombia, and Ecuador [1]. The species is endemic to the Humboldt Current Region, restricted to cool, nutrient-rich waters [2], and has been listed as a vulnerable species by the International Union for Conservation of Nature (IUCN) due to overfishing, climate change, and ocean acidification. Humboldt Penguins are commonly exhibited in zoos and aquaria around 
the world, and it is important to ensure good welfare in captivity. Birds in captivity are potentially exposed to a variety of stressors, such as visitors or inclement weather.

Stress is the physiological response elicited when an individual perceives a threat to its homeostasis [3]. Novel, minimally invasive, and efficient methods of monitoring stress and discomfort in animals held in captivity is of increasing scientific interest due to the increase in public concern and ethical issues regarding the welfare of captive animals [4]. Part of the stress response is an increase in the secretion of the glucocorticoid hormone corticosterone (CORT) from the adrenal gland [5-7]. This hormone is metabolized by the liver and excreted through the feces via bile [4]. The major glucocorticoids secreted by the adrenal glands are corticosterone and cortisol, with corticosterone being more predominant in avian species [8]. Quantification of blood corticosterone levels can provide an accurate measurement of stress in birds. However, the act of blood collection can cause a significant increase in the plasma corticosterone levels due to the stress from capturing, handling, restraint, and phlebotomy [9]. A less invasive alternative is the measurement of glucocorticoid metabolites in the feces. This method is non-invasive and sample collection is easy, with no implications on the bird's behavior or endocrine status [10]. Plasma corticosterone levels and the corresponding fecal glucocorticoid metabolites have been shown to increase in tandem to induced stress [11]. However, there is a time delay between the stimulation of the hypothalamic-pituitary-adrenal (HPA) axis and increase in fecal glucocorticoid excretion [12]. This delay is affected by several factors, such as species, digestion time, and feed intake [13]. In African Penguins (Spheniscus demersus), the delay was found to be 5.5 to $8 \mathrm{~h}$ after a stressful event [14], whereas in Adélie Penguins (Pygoscelis adeliae), it was found to be 6 to $18 \mathrm{~h}$ [15].

Advancements in biotelemetry technology, particularly advancements related to biologgers, such as the increment of memory capacity [16] and the miniaturization of these devices $[17,18]$, revolutionized biological research by allowing biologging to be applied to animals of all sizes and in different environments [18]. Devices that also log data, such as dive depth and swimming speed, have also allowed the swimming behavior of penguins to be studied [19]. However, despite these advances, biologgers can still potentially cause pain and distress to the animal being studied. Although minimal changes were found in swimming behavior between instrumented and non-instrumented penguins [20], some studies have demonstrated other detrimental effects of externally attached biologgers on penguins, such as increased hydrodynamic drag [21,22], increased energy expenditure when swimming [23], increased mortality [24], and decreased reproductive output [25]. Penguins with externally attached biologgers were also observed to exhibit an increase in behaviors such as preening, stretching, and fluffing compared to penguins without biologgers [25].

This study investigated the use of immunoreactive fecal glucocorticoid metabolite (FGCM) measurements of Humboldt Penguins as an accurate and reliable indication of stress, as well as the effects of accelerometer vests on fecal glucocorticoid metabolite levels. We hypothesized that stress caused by capture and transport would result in an increase in fecal glucocorticoid metabolite levels. We also hypothesized that accelerometer vests would be a stressor and cause an increase in FGCM levels. The studies were performed under animal research approval codes WRS170801, for the fecal corticosterone project, and WRS180601, for the vest project.

\section{Materials and Methods}

\subsection{Sample Collection}

Over a 4-month period, fecal samples were randomly and opportunistically collected within $2 \mathrm{~h}$ of defecation from the Humboldt Penguin exhibit at Jurong Bird Park, Singapore, between 3 p.m. to 5 p.m. daily. There were nine male and nine female King Penguins (Aptenodytes patagonicus), one male Southern Rockhopper Penguin (Eudyptes chrysocome), one male and one female Macaroni Penguins (Eudyptes chrysolophus), and seven male, seven female, and nine unknown sex Humboldt Penguins of mixed age in the exhibit. 
This population structure did not change throughout the study. Each day, the feces from Humboldt Penguins only were collected as a pool without identifying the penguin that the sample was from in order to utilize a 'population fecal sample' for monitoring the stress levels of the entire captive Humboldt Penguin population. Feces were only collected after visual confirmation of defecation from Humboldt Penguins. There were three capture and transport events during this 4-month period. The penguins were caught by hand after herding them into a smaller area and then transported in individual carry cages. The carry cages were then moved by hand to the holding containers, which were located less than 1 min by foot from the exhibit. There was an additional day when penguins were handled by a veterinarian. These four cases are classified as "stress events".

For a separate 1-month period, six Humboldt Penguins were chosen for accelerometer vest placement; during this time, fresh fecal samples were collected from them in the same way. These accelerometer vests were made from a diving suit. Fecal samples were collected on the days the vest was placed on each penguin, as well as the days before and after application of the vest. All samples were stored at $-20{ }^{\circ} \mathrm{C}$ before laboratory processing and analyses.

\subsection{Analysis of Fecal Glucocorticoid Metabolites (ELISA)}

FGCMs were extracted using a modified version of a previously published protocol [26]. Fecal samples were air-dried for $24 \mathrm{~h}$ using a lyophilizer (Labconco, Kansas City, MO, USA). Samples were pulverized into a powder-like form with large pieces of debris and other non-fecal material removed. Clean and dried feces $(0.2 \mathrm{~g})$ were then weighed and collected into $16 \mathrm{~mm} \times 125 \mathrm{~mm}(19-\mathrm{mL})$ glass tubes. To each glass tube with $0.2 \mathrm{~g}$ of feces, $5 \mathrm{~mL}$ of $70 \%$ ethanol were added, tube contents were mixed using a vortex (Biomedia, Singapore), and then vortexed again using pulse mode in a multi-tube vortex lyophilizer (Labconco, Kansas City, MO, USA). Samples were then centrifuged at $2500 \mathrm{rpm}$ for $20 \mathrm{~min}$. The supernatant was then extracted and aliquoted into new16 mm $\times 125 \mathrm{~mm}(19-\mathrm{mL})$ glass tubes. Glass tubes with $0.2 \mathrm{~g}$ of feces were resuspended in $5 \mathrm{~mL}$ of $70 \%$ ethanol one more time, and vortexed and centrifuged as previously described, excluding the step using the multi-tube vortex. The second supernatant was collected and added to the previously collected supernatant.

Extracted samples were dried with a sample concentrator (Stuart ${ }^{\circledR}$, Staffordshire, UK) for $24 \mathrm{~h}$. Once dried, samples were reconstituted in $1 \mathrm{~mL}$ of enzyme-linked immunosorbent assay (ELISA) phosphate buffered saline (PBS) (Arbor Assays ${ }^{\circledR}$, Ann Arbor, MI, USA) and vortexed until no extract was present on the sides of the tubes. The final supernatant was collected and aliquoted into 1.5-mL plastic microcentrifuge tubes (Simport ${ }^{\circledR}$, Beloeil, QC, Canada) and stored at $-20{ }^{\circ} \mathrm{C}$ until further processing.

Corticosterone (CORT) antibody and horseradish peroxidase (HRP) stocks (C. Munro, UC Davis, CA, USA) were diluted to $1: 1000$ by adding $10 \mu \mathrm{L}$ of stock to $9.990 \mathrm{~mL}$ ELISA assay buffer (Arbor Assays ${ }^{\circledR}$, Ann Arbor, MI, USA). ELISA standards (500, 250, 125, 62.5, $31.25,15.6,7.8,3.9 \mathrm{pg} /$ well) were obtained by serially diluting the standard stock of 1000 pg/well (Steraloids, Newport, RI, USA) 2-fold using $200 \mu \mathrm{L}$ of standard stock solution and $200 \mu \mathrm{L}$ of ELISA assay buffer (Arbor Assays ${ }^{\circledR}$, Ann Arbor, MI, USA). Fecal samples were thawed and diluted to the appropriate dilution (1:50) by adding $20 \mu \mathrm{L}$ of sample to $980 \mu \mathrm{L}$ of ELISA assay buffer (Arbor Assays ${ }^{\circledR}$, Ann Arbor, MI, USA).

Preparation of the ELISA assay was done by diluting HRP (1:1000) to a working dilution of 1:45,000 by adding $68.2 \mu \mathrm{L}$ of stock HRP to $3 \mathrm{~mL}$ of ELISA assay buffer (Arbor Assays $^{\circledR}$, Ann Arbor, MI, USA), and corticosterone antibody (1:1000) to a working dilution of $1: 60,000$ by adding $50 \mu \mathrm{L}$ of stock to $3 \mathrm{~mL}$ of ELISA assay buffer (Arbor Assays ${ }^{\circledR}$, Ann Arbor, MI, USA). The polyclonal CJM006 antibody used was reported to cross-react with corticosterone $(100 \%)$, desoxycorticosterone $(14.25 \%)$, progesterone $(2.65 \%)$, tetrahydrocorticosterone $(0.90 \%)$, testosterone $(0.64 \%)$, cortisol $(0.23 \%)$, prednisolone $(0.07 \%), 11$ desoxycortisol $(0.03 \%)$, prednisone $(<0.01 \%)$, cortisone $(<0.01 \%)$, and estradiol $(<0.01 \%)$ [9]. Standards, samples, and controls were prepared in a pre-coated goat-anti rabbit IgG ELISA 
plate (Thermo Fisher Scientific, Waltham, MA, USA) by aliquoting $50 \mu \mathrm{L}$ of each in separate wells.

To each well, $25 \mu \mathrm{L}$ of diluted HRP $(1: 45,000)$ followed by $25 \mu \mathrm{L}$ of diluted antibody $(1: 60,000)$ were immediately added, except for non-specific binding (NSB) wells A1 and B1. Plates were then incubated on an orbital shaker (Stuart ${ }^{\circledR}$, Staffordshire, UK) at room temperature for $1 \mathrm{~h}$. After incubation, the ELISA plate was washed four times with wash solution (Arbor Assays ${ }^{\circledR}$, Ann Arbor, MI, USA) and blot dried. One phosphate-citrate buffer with sodium perborate tablet (Sigma-Aldrich ${ }^{\circledR}$, Darmstadt, Germany) was dissolved in $100 \mathrm{~mL}$ purified water, and $10 \mathrm{~mL}$ were added to one 3,3,5,5-tetramethylbenzidine (TMB) tablet (Sigma-Aldrich ${ }^{\circledR}$, Darmstadt, Germany) and left to dissolve in the absence of light. TMB $(100 \mu \mathrm{L})$ was aliquoted to all wells and left to incubate at room temperature for $30 \mathrm{~min}$. STOP solution $(50 \mu \mathrm{L})$ (Merck, Darmstadt, Germany) was then added to all wells. The ELISA plate was read at $450 \mathrm{~nm}$ using Magellan ${ }^{\mathrm{TM}}$ (Tecan, Männedorf, Switzerland). All standards and samples were measured in duplicate. Parallelism tests were conducted by serially diluting an equal volume of extracts from selected timepoints combined together and comparing it to a serial dilution of the corticosterone standard. The slopes of the relationships between percent binding and relative dilution for the standard solution and pooled penguin feces were not significantly different $\left(\mathrm{F}_{1,14}=3.065, p=0.1019\right)$. The amount of FGCMs per gram of dry feces was calculated based on the results. A total of seven assays were run. Inter-assay coefficients of variation $(\mathrm{CV})$ for both high and low controls were $\leq 15 \%$, and intra-assay CVs were $\leq 10 \%$.

\subsection{Statistical Analysis}

Outliers in the FGCM levels were identified using an iterative process in which high and low values were eliminated if they exceeded the range of the mean $\pm 2 S D$ [27]. The baseline range was then established by obtaining a mean $(n=29)$ of the FGCM values after all the outliers had been excluded [27]. The following stressful events were identified during this period:

1. Transport from holding containers to the exhibit (4 August 2017)

2. Veterinary examination (8 August 2017)

3. Transport from the exhibit to holding containers (18 August 2017)

4. Transport from holding containers to the exhibit (22 September 2017).

The 3 days following each of the above stressful events (excluding the day of the stress event itself) were classified as stressful days. The rest of the days were classified as non-stressful days. The effects of simulated stressful events on fecal corticosterone were analyzed on a population level using independent sample $T$-tests with pooled data for stressful/non-stressful periods, where individual animals were not identified. In this case, samples were randomly collected from the exhibit and not linked to individual animals, in keeping with our population level approach. A generalized linear model univariate approach was used to test for the effect of the accelerometer (vest on/off) on fecal CORT in a separate experiment, with individual animal, air conditioning status, and molt status as random factors. Date was also included as a covariate in initial models. SPSS Statistics version 25 (IBM, Armonk, NY, USA) was used for statistical analyses.

\section{Results}

\subsection{Capture/Transport Stress}

The baseline FGCM level was $164.76 \mathrm{ng} / \mathrm{g}$ feces. The upper limit (baseline $+2 S D$ ) of the baseline FGCM level was $233.62 \mathrm{ng} / \mathrm{g}$ feces. There were increases in the FGCM levels above the upper range of the baseline during the stressful events listed in Section 2.3.

FGCM levels increased above baseline $+2 S D 1$ day after each stressful event and returned to below baseline $+2 S D$ within 3 to 7 days of the event.

There were six increases in FGCM levels that exceeded the baseline $+2 S D$ of $233.62 \mathrm{ng} / \mathrm{g}$ (Figure 1). Four of these increases corresponded with the stress events described above. 


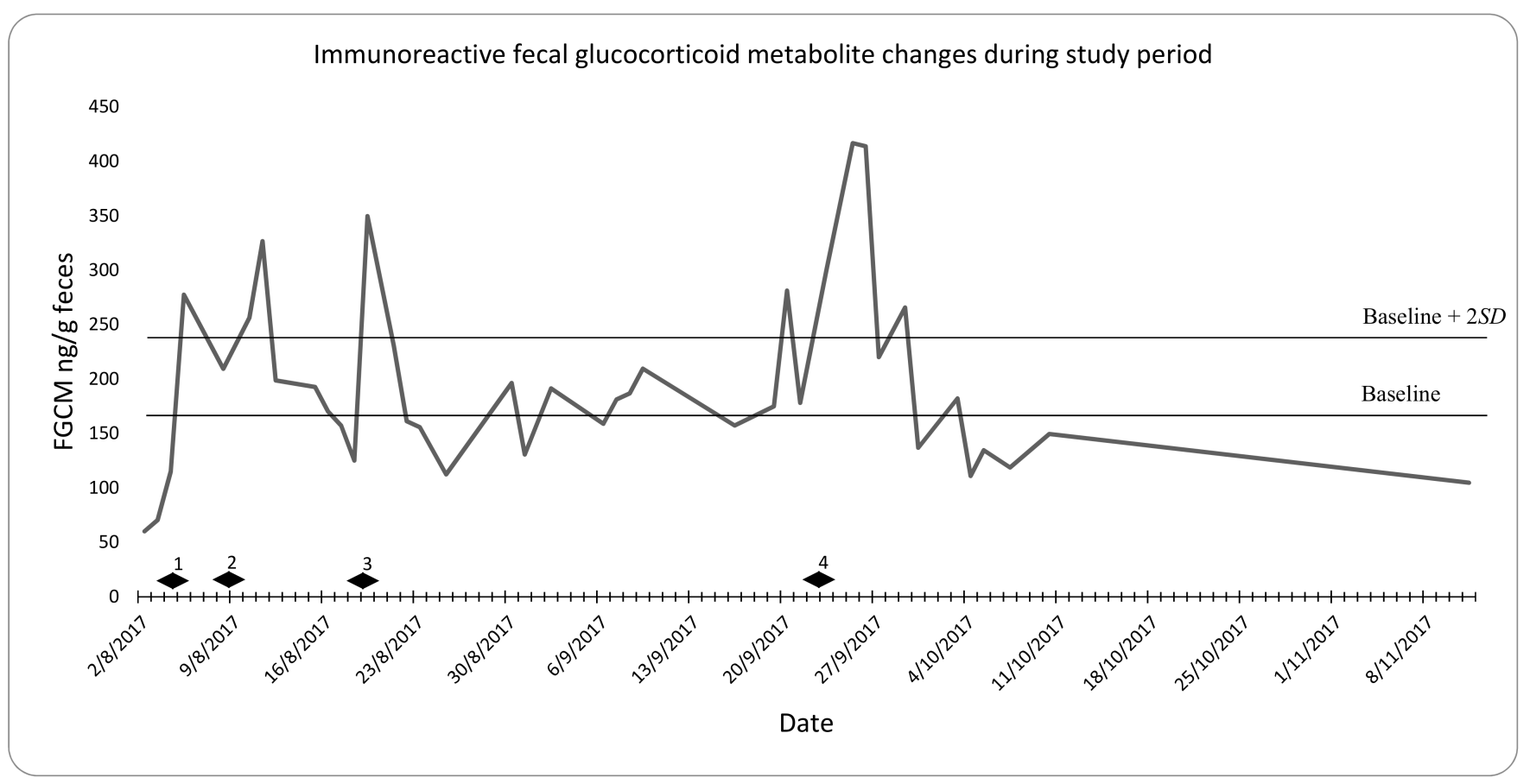

Figure 1. Daily pooled sample fecal glucocorticoid metabolite (FGCM) concentrations during study period. Diamonds indicate stress events (1. transport from holding containers to the exhibit; 2 . veterinary examination; 3 . transport from the exhibit to holding containers; 4 . transport from holding containers to the exhibit).

The FGCM levels were significantly higher on the days classified as likely high stress (i.e., 3 days after each stressful event; $308.31 \pm 62.58 \mathrm{ng} / \mathrm{g}$ of feces, $n=7$ ) compared to days where no stressors were expected $(170.15 \pm 65.06 \mathrm{ng} / \mathrm{g}$ of feces, $n=33 ; t=-5.13$, $p<0.0001$, Figure 2).

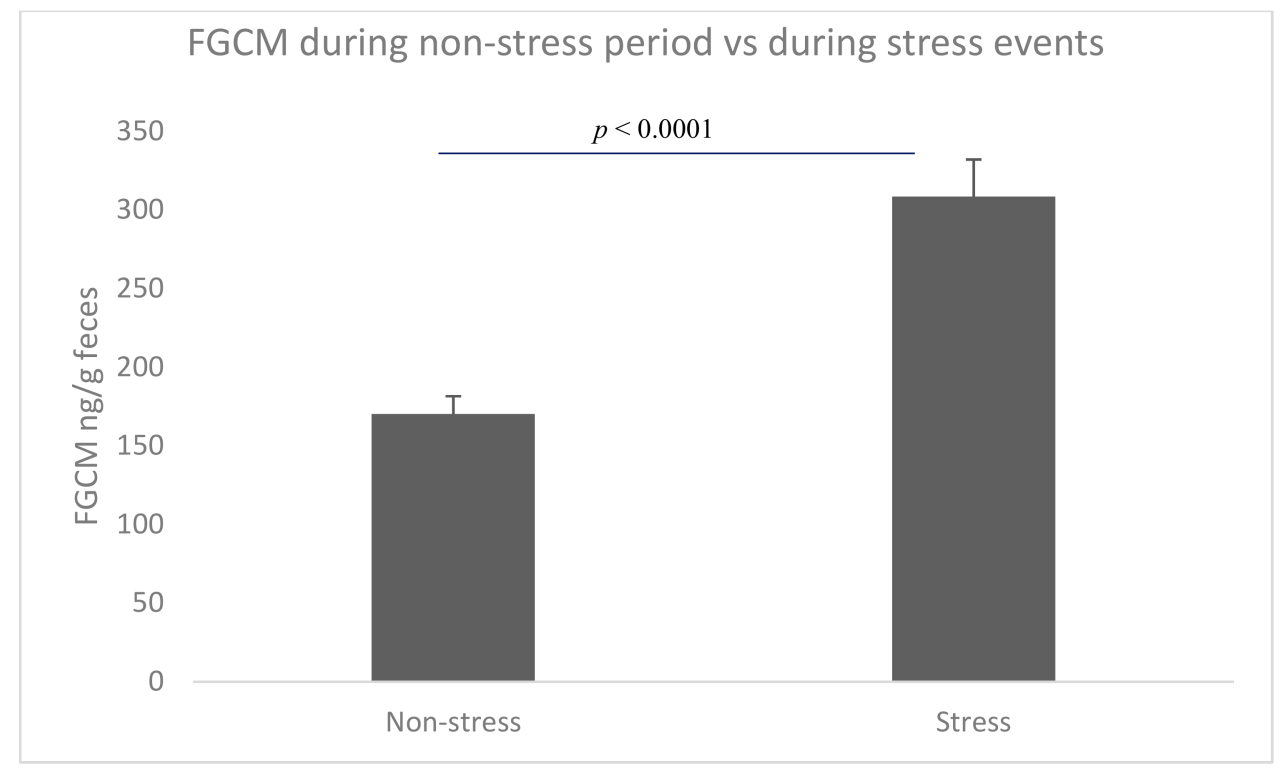

Figure 2. Fecal glucocorticoid metabolite levels during non-stressful vs. stressful periods.

\subsection{Accelerometer Vest Application}

As this part of the study was performed in a separate time period, the results were not included in the analysis of the baseline in Figure 1. There were no significant differences in FGCM levels amongst periods (Figure 3) before the accelerometer vest was fitted (538.35 $\pm 60.87 \mathrm{ng} / \mathrm{g}$ of feces, $n=43$ days) compared to when the vest was on (501.87 \pm 
$127.24 \mathrm{ng} / \mathrm{g}$ of feces, $n=11$ days) or after the vest was removed (546.60 $\pm 95.87 \mathrm{ng} / \mathrm{g}$ of feces, $n=24$ days; $\left.F_{2,15}=0.056, p=0.946\right)$. There was a significant effect of individual bird ID on FGCM levels $\left(\mathrm{F}_{5,17}=3.458, p=0.024\right)$, but individual pairwise comparisons were not significant after Bonferroni adjustment, and there was no significant interaction between individual ID and vest status $\left(\mathrm{F}_{10,60}=0.723, p=0.700\right)$. When before and after vest data were combined into one 'vest-off' category, there were no significant effects of air conditioning status $\left(\mathrm{F}_{1,64}=2.499, p=0.119\right)$ or molting $\left(\mathrm{F}_{1,64}=0.073, p=0.787\right)$ on FGCM.

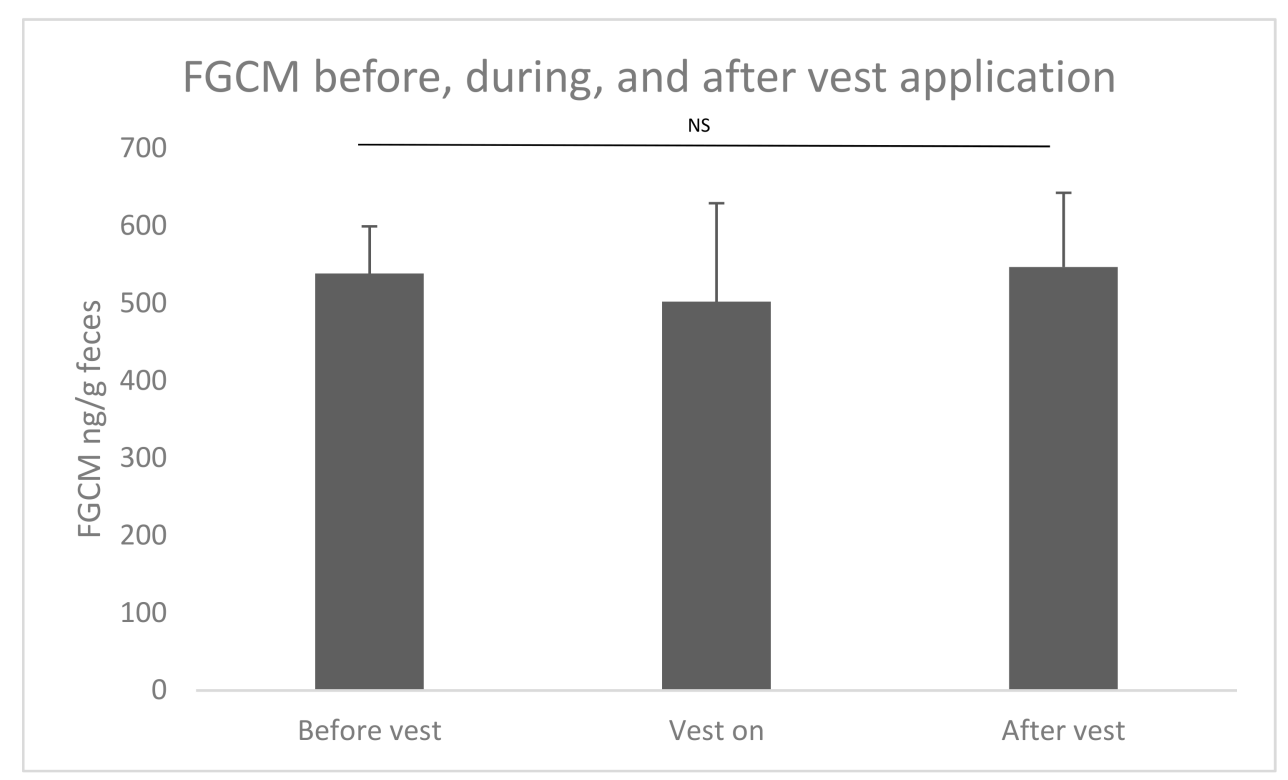

Figure 3. Fecal glucocorticoid metabolite levels with before, during, and after vest application. NS: not significant.

\section{Discussion}

The results supported our hypothesis that stress caused by capture and transport would result in an increase in FGCM levels. This demonstrated that FGCM measurement using a non-competitive ELISA was a reliable and repeatable technique to assess the physiological stress status of Humboldt Penguins. The results did not support our hypothesis that accelerometer vests would be a stressor and cause an increase in FGCM levels.

Means of monitoring the stress levels of captive animals is important in ensuring their welfare under human care. It is even more important that these means do not result in stress to the animals being monitored. Fecal collection has been shown in this study to not affect the FGCM levels, whereas restraint and transport do. FGCM measurement is therefore a useful way to quantify the stress levels of captive Humboldt Penguins. However, as FGCM levels remain high for 3 to 7 days after a stressful event, it is unknown how multiple stressful events, which may be more reflective of a real-world situation, can affect FGCM levels. Future studies should investigate the effects of cumulative stress events on fecal CORT. Even so, regularly measured FGCM levels, combined with carefully recorded husbandry records, can help identify stressful periods in the lives of captive Humboldt Penguins so that appropriate precautions can be made to mitigate the consequences of such stressful periods (e.g., increased susceptibility to disease). The methods of this study were different from those of previous validation studies in other penguin species in that previous studies measured FGCM levels from the feces of individual penguins $[4,13,14,27,28]$, whereas the feces in this study were collected as a pool without identifying the penguin that the sample was from. Utilizing a 'population fecal sample', this study showed that increases in FGCM levels at a population level still corresponded with stressful events. This provides the basis for monitoring the stress levels of a captive population of penguins, which is more likely to be utilized in a zoological institution than the analysis of FGCM levels of individual penguins for cost and logistical reasons. 
The baseline (vest-off) FGCM levels appeared to be higher in this part of the study compared to the baseline FGCM levels for the initial study. However, as the latter study was performed at a different time of the year, the baseline FGCM levels should be interpreted separately as many other factors, such as hormonal status and environmental conditions, can affect baseline FGCM levels [28,29]. For example, high levels of glucocorticoids were directly correlated with the temperature-humidity index in captive African Penguins [30]. However, it is also possible that this difference is due to inter-assay variation. This study also demonstrated that vests as means of attaching biologgers to Humboldt Penguins do not result in increases in FGCM levels. This helps in the ethical consideration when using such devices. Stress can also alter the behavior of animals and affect the parameters being monitored by the biologgers. The way each parameter can be affected is currently poorly understood and should be investigated in future studies. Furthermore, as this study was not a full validation of the assay, a controlled study demonstrating that FGCM levels are increased in individual Humboldt Penguins is required to provide full physiological evidence. Such a validation is beyond the scope of this study, which provided preliminary evidence of the biological significance of FGCM increases of a Humboldt Penguin colony in relation to stressful events.

In conclusion, the results of this study show that regular monitoring of FGCM levels can be a useful way of monitoring stress in captive Humboldt Penguins, and the use of vests as means of attaching biologgers that can monitor other physiological and behavioral parameters as part of a more comprehensive monitoring program will not cause an increase in FGCM levels. This information can help zoological institutions make decisions about the level of monitoring they would like to implement in their captive Humboldt Penguin populations.

Author Contributions: Conceptualization: S.X.; methodology: S.X.; software: T.J.M.; validation: S.X. and T.J.M.; formal analysis: T.J.M.; investigation: S.X.; resources: S.X.; data curation: S.X.; writing-original draft preparation: S.X. and T.J.M.; writing—review and editing: S.X. and T.J.M.; visualization: S.X. and T.J.M.; supervision: S.X.; project administration: S.X.; funding acquisition: S.X. Both authors have read and agreed to the published version of the manuscript.

Funding: This research received no external funding.

Institutional Review Board Statement: The study was conducted according to the guidelines of the Declaration of Helsinki, and approved by the Research Advisory Panel of Wildlife Reserves Singapore (protocol code WRS170801 on 1/8/2017, for the fecal corticosterone project, and WRS180601 on $1 / 8 / 2018$, for the vest project).

Informed Consent Statement: Not applicable.

Data Availability Statement: The data presented in this study are available on request from the corresponding author. The data are not publicly available due to Wildlife Reserves Singapore policy.

Acknowledgments: We would like to thank the veterinary and zoology teams at Wildlife Reserves Singapore that were involved in the study. We would like to also thank the WRS laboratory staff, especially Josephine Kawi, and Ngee Ann Polytechnic students, Justin Yip Jeng Teng and Clara Chue Yixin, involved in the collection, processing, and analyses of the samples.

Conflicts of Interest: The authors declare no conflict of interest. The funders had no role in the design of the study; in the collection, analyses, or interpretation of data; in the writing of the manuscript, or in the decision to publish the results.

\section{References}

1. Ridgely, R.S.; Greenfield, P.J. The Birds of Ecuador: Status, Distribution, and Taxonomy; Cornell University Press: New York, NY, USA, 2001; Volume 1.

2. Williams, T.D.; Busby, J. Bird Families of the World. 2. The Penguins: Spheniscidae; Oxford University Press: Oxford, UK, 1995.

3. Hulsman, A.; Dalerum, F.; Ganswindt, A.; Muenscher, S.; Bertschinger, H.J.; Paris, M. Non-invasive monitoring of glucocorticoid metabolites in brown hyaena (Hyaena brunnea) feces. Zoo Biol. 2011, 30, 451-458. [CrossRef] [PubMed]

4. Anfossi, L.; Ozella, L.; Di Nardo, F.; Giovannoli, C.; Passini, C.; Favaro, L.; Pessani, D.; Mostl, E.; Baggiani, C. A broad-selective enzyme immunoassay for non-invasive stress assessment in African penguins (Spheniscus demersus) held in captivity. Anal. Methods 2014, 6, 8222-8231. [CrossRef] 
5. Walker, B.G.; Dee Boersma, P.; Wingfield, J.C. Habituation of adult Magellanic penguins to human visitation as expressed through behavior and corticosterone secretion. Conserv. Biol. 2006, 20, 146-154. [CrossRef] [PubMed]

6. Hood, L.C.; Boersma, P.D.; Wingfield, J.C. The adrenocortical response to stress in incubating Magellanic penguins (Spheniscus magellanicus). Auk 1998, 115, 76-84.

7. Carroll, G.; Turner, E.; Dann, P.; Harcourt, R. Prior exposure to capture heightens the corticosterone and behavioural responses of little penguins (Eudyptula minor) to acute stress. Conserv. Physiol. 2016, 4. [CrossRef]

8. Mostl, E.; Rettenbacher, S.; Palme, R. Measurement of corticosterone metabolites in birds' droppings: An analytical approach. Ann. N. Y. Acad. Sci. 2005, 1046, 17-34. [CrossRef]

9. Watson, R.; Munro, C.; Edwards, K.L.; Norton, V.; Brown, J.L.; Walker, S.L. Development of a versatile enzyme immunoassay for non-invasive assessment of glucocorticoid metabolites in a diversity of taxonomic species. Gen. Comp. Endocrinol. 2013, 186, 16-24. [CrossRef] [PubMed]

10. Touma, C.; Palme, R. Measuring fecal glucocorticoid metabolites in mammals and birds: The importance of validation. Ann. N. Y. Acad. Sci. 2005, 1046, 54-74. [CrossRef]

11. Dehnhard, M.; Schreer, A.; Krone, O.; Jewgenow, K.; Krause, M.; Grossmann, R. Measurement of plasma corticosterone and fecal glucocorticoid metabolites in the chicken (Gallus domesticus), the great cormorant (Phalacrocorax carbo), and the goshawk (Accipiter gentilis). Gen. Comp. Endocrinol. 2003, 131, 345-352. [CrossRef]

12. Narayan, E.J.; Webster, K.; Nicolson, V.; Mucci, A.; Hero, J.-M. Non-invasive evaluation of physiological stress in an iconic Australian marsupial: The Koala (Phascolarctos cinereus). Gen. Comp. Endocrinol. 2013, 187, 39-47. [CrossRef]

13. Palme, R. Measuring fecal steroids: guidelines for practical application. Ann. N. Y. Acad. Sci. 2005, 1046, 75-80. [CrossRef] [PubMed]

14. Ozella, L.; Anfossi, L.; Di Nardo, F.; Pessani, D. Non-invasive monitoring of adrenocortical activity in captive African Penguin (Spheniscus demersus) by measuring faecal glucocorticoid metabolites. Gen. Comp. Endocrinol. 2015, 224, 104-112. [CrossRef]

15. Nakagawa, S.; Möstl, E.; Waas, J.R. Validation of an enzyme immunoassay to measure faecal glucocorticoid metabolites from Adelie penguins (Pygoscelis adeliae): A non-invasive tool for estimating stress? Polar Biol. 2003, 26, 491-493. [CrossRef]

16. Ponganis, P.J. Bio-logging of physiological parameters in higher marine vertebrates. Deep Sea Res. Part II Top. Stud. Oceanogr. 2007, 54, 183-192. [CrossRef]

17. Kooyman, G.; Cherel, Y.; Maho, Y.L.; Croxall, J.; Thorson, P.; Ridoux, V.; Kooyman, C. Diving behavior and energetics during foraging cycles in king penguins. Ecol. Monogr. 1992, 62, 143-163. [CrossRef]

18. Ropert-Coudert, Y.; Beaulieu, M.; Hanuise, N.; Kato, A. Diving into the world of biologging. Endanger. Species Res. 2009, 10, 21-27. [CrossRef]

19. Yoda, K.; Naito, Y.; Sato, K.; Takahashi, A.; Nishikawa, J.; Ropert-Coudert, Y.; Kurita, M.; Le Maho, Y. A new technique for monitoring the behaviour of free-ranging Adelie penguins. J. Exp. Biol. 2001, 204, 685-690. [PubMed]

20. Yoda, K.; Sato, K.; Niizuma, Y.; Kurita, M.; Bost, C.; Le Maho, Y.; Naito, Y. Precise monitoring of porpoising behaviour of Adélie penguins determined using acceleration data loggers. J. Exp. Biol. 1999, 202, 3121-3126.

21. Wilson, R.P.; Grant, W.S.; Duffy, D.C. Recording devices on free-ranging marine animals: Does measurement affect foraging performance? Ecology 1986, 67, 1091-1093. [CrossRef]

22. Kooyman, G.L. Diverse Divers: Physiology and Behavior; Springer: Berlin/Heidelberg, Germany, 2012 ; Volume 23.

23. Ropert-Coudert, Y.; Knott, N.; Chiaradia, A.; Kato, A. How do different data logger sizes and attachment positions affect the diving behaviour of little penguins? Deep Sea Res. Part II Top. Stud. Oceanogr. 2007, 54, 415-423. [CrossRef]

24. Saraux, C.; Le Bohec, C.; Durant, J.M.; Viblanc, V.A.; Gauthier-Clerc, M.; Beaune, D.; Park, Y.-H.; Yoccoz, N.G.; Stenseth, N.C.; Le Maho, Y. Reliability of flipper-banded penguins as indicators of climate change. Nature 2011, 469, 203-206. [CrossRef] [PubMed]

25. White, C.R.; Cassey, P.; Schimpf, N.G.; Halsey, L.G.; Green, J.A.; Portugal, S.J. Implantation reduces the negative effects of bio-logging devices on birds. J. Exp. Biol. 2013, 216, 537-542. [CrossRef] [PubMed]

26. Brown, M.E.; Converse, S.J.; Chandler, J.N.; Shafer, C.; Brown, J.L.; Keefer, C.L.; Songsasen, N. Female gonadal hormones and reproductive behaviors as key determinants of successful reproductive output of breeding whooping cranes (Grus americana). Gen. Comp. Endocrinol. 2016, 230, 158-165. [CrossRef] [PubMed]

27. Brown, J.L.; Wasser, S.K.; Wildt, D.E.; Graham, L.H. Comparative aspects of steroid hormone metabolism and ovarian activity in felids, measured noninvasively in feces. Biol. Reprod. 1994, 51, 776-786. [CrossRef] [PubMed]

28. Romero, L.M.; Reed, J.M. Repeatability of baseline corticosterone concentrations. Gen. Comp. Endocrinol. 2008, 156, 27-33. [CrossRef]

29. Angelier, F.; Wingfield, J.C.; Weimerskirch, H.; Chastel, O. Hormonal correlates of individual quality in a long-lived bird: A test of the 'corticosterone-fitness hypothesis'. Biol. Lett. 2010, 6, 846-849. [CrossRef] [PubMed]

30. Ozella, L.; Anfossi, L.; Di Nardo, F.; Pessani, D. Effect of weather conditions and presence of visitors on adrenocortical activity in captive African penguins (Spheniscus demersus). Gen. Comp. Endocrinol. 2017, 242, 49-58. [CrossRef] 